\title{
THE ROLE OF ACALYPHA INDICA LINN. EXTRACT ON HEART RATES WITH MYASTHENIA GRAVIS RAT MODEL
}

\section{DESAK GEDE BUDI KRISNAMURTI ${ }^{1}$, RANI WARDANI HAKIM ${ }^{1}$, RADIANA DHEWAYANI ANTARIANTO ${ }^{2}$, SITI FARIDA ${ }^{1}$, ERNI HERNAWATI PURWANINGSIH ${ }^{1}$, JAN SUDIR PURBA ${ }^{3 *}$}

\author{
${ }^{1}$ Department of Medical Pharmacy, Faculty of Medicine, Universitas Indonesia, Jakarta, Indonesia. ${ }^{2}$ Department of Histology, Faculty of \\ Medicine, Universitas Indonesia, Jakarta, Indonesia. ${ }^{3}$ Department of Neurology, Universitas Indonesia, Jakarta, Indonesia. \\ Email: jansudir@yahoo.com
}

Received: 22 March 2017, Revised and Accepted: 13 October 2017

\section{ABSTRACT}

Objective: Myasthenia gravis (MG) is an autoimmune disease of the neuromuscular junction (NMJ) caused by antibodies that attack components of the postsynaptic membrane, impair neuromuscular transmission, and lead to weakness and fatigue of skeletal muscle. Acetylcholine is also used as a neurotransmitter in the autonomic nervous system. Striated cardiac muscle can be a target for immune attack manifesting as heart failure, arrhythmia, and sudden death. Involvement of the heart rate (HR) has been claimed and reported, but a causal connection between MG and altered cardiac function has not been found.

Methods: For this study of experimental autoimmune MG (EAMG) is used rocuronium, prostigmine, and Acalypha indica (AI) Linn. compared with HR.

Results: From the results, the study found that sympathetic activity of HR variability in EAMG injected with rocuronium $10 \mathrm{mg} / \mathrm{kg}$ body weight (BW) in 10 min significantly found increasing in measures of short-term variations in HR variability, indicating parasympathetic impairment.

Conclusion: We conclude that in MG, cholinergic transmission is affected more diffusely than previously thought. Furthermore, AI was given orally $30 \mathrm{mg} / \mathrm{kg}$ BW has an effect similar to the injecting of prostigmine $10 \mathrm{mg} / \mathrm{kg}$ BW that can reduce HR. Driven by the fact that the pharmacological treatment of MG is unsatisfied, it needs the therapeutic development for MG using herbal ingredients of AI. This means that the AI compositions containing anti-MG whose composition should be investigated for the next research.

Keywords: Myasthenia gravis, Extract Acalypha indica Linn., Acetylcholine receptor antibody, Autoimmune disease, Neuromuscular junction, Heart rate.

(c) 2018 The Authors. Published by Innovare Academic Sciences Pvt Ltd. This is an open access article under the CC BY license (http://creativecommons. org/licenses/by/4. 0/) DOI: http://dx.doi.org/10.22159/ajpcr.2018.v11i1.18616

\section{INTRODUCTION}

Myasthenia gravis (MG) is an autoimmune neuromuscular transmission disorder characterized by loss of acetylcholine receptor (AChR) functionality arising from the action of AChR antibody $(\mathrm{Ab})[1,2]$. Antibodies to the nicotinic AChR destroy the AChR, thus leading to defective neuromuscular transmission of electrical impulse and to muscle weakness. Acetylcholine is an organic chemical that functions in the brain and body of many types of animals, including humans, as a neurotransmitter used at the neuromuscular junction (NMJ). This property means that drugs that affect cholinergic systems can have very dangerous effects ranging from paralysis to convulsions [3]. Acetylcholine is also used as a neurotransmitter in the autonomic nervous system, both as an internal transmitter for the sympathetic nervous system and as the final product released by the parasympathetic nervous system. Striated cardiac muscle can be a target for immune attack manifesting as heart failure, arrhythmia, and sudden death. Involvement of the heart has been claimed and reported, but a causal connection between MG and altered cardiac function has not been found. Furthermore, the sympathetic activity of HR variability did not differ significantly between patients and controls; however, a significant decrease in measures of short-term vagal variations in HR variability was noted indicating parasympathetic impairment [4,5]. Mygland et al. [6] demonstrated that the existence of heart muscle antibodies was related to a type of MG, in finding such antibodies in MG patients with thymoma and late-onset MG, but not in early-onset MG. These heart muscle antibodies were shown to be specific for MG. Lately, the discovery of antibodies to the muscle-specific tyrosine kinase (MuSK) has identified a subgroup of MG patients with rather distinct clinical characteristics [7]. Cardiac function has not been examined specifically in MuSK-positive MG patients. However, MG is known to involve other body systems including the heart. Cardiac involvement in MG may take several forms, ranging from asymptomatic electrocardiograph (ECG) changes to ventricular tachycardia, myocarditis, conduction disorders, heart failure, and sudden death [8]. Furthermore, MG patients have a higher prevalence of cardiac manifestations in the presence of thymoma (10-15\%) [9]. Since the preganglionic neuron diverges the information to more neurons in the case of a sympathetic system in contrast to that of a parasympathetic system where the preganglionic fibers contact a few postganglionic neurons, the impact can be postulated to be small in case of a sympathetic nervous system than a parasympathetic function [10]. The cardiovascular effects of these neuromuscular blocking agents have been investigated in different studies. The experimental autoimmune MG (EAMG) can be induced in mice and rats of susceptible strains that show clinical symptoms mimicking the human disease. While the prevailing clinical finding of $M G$ is muscle fatigue and weakness and autonomic dysfunction [11-13]. Both positive inotropic and chronotropic effects have been reported after pancuronium administration $[14,15]$ by increased $\mathrm{HR}$ and arterial blood pressure $[16,17]$. The EAMG is most frequently detected by clinical evaluation of muscle weakness of the mouse and the ability of neostigmine (an acetylcholinesterase inhibitor) to reverse the manifestations of a disease. Drugs that competitively inhibit acetylcholinesterase (e.g., neostigmine, physostigmine, or primarily pyridostigmine) are effective in treating this disorder. They allow endogenously released acetylcholine more time to interact with its 
respective receptor before being inactivated by acetylcholinesterase in the synaptic cleft (the space between nerve and muscle). Animal experiments show that MuSK immunoglobulin G (IgG) can cause MG. Mice that received repeated daily injections of patient IgG showed impaired neuromuscular transmission, with reductions in endplate AChR [18-20]. Similar changes to endplates were reported in mice, rats, and rabbits that were actively immunized with MuSK [21,22].

Driven by the fact that the pharmacological treatment of MG either can only treat the disease partially (anticholinesterases) or for other group of drugs (immunosuppressants) will result in major side effects, limited desired therapeutic effect from thymectomy, effects of intravenous (IV) Ig and plasmapheresis that can only last for short time, and enormously high cost of treatment, the needs, and urgency for alternative treatment for MG has become more and more important [23].

Many drugs used currently are expensive and may also have side effects on prolonged usage. These forced researchers to search drugs, which the price is relatively cheap, safe, and biodegradable, have fewer side effects and which will be able to act for longer periods before resistance sets in. Plants are the basic source of knowledge of modern medicine. Many studies have shown the role of herbal medicine used for the treatment of various diseases. Kassab et al. [24] found that the aqueous extract of clove (Syzygium aromaticum) has neuroprotective effects in rats with aluminum-induces neurotoxicity. Furthermore, Kukkar et al. [25] suggested that methanolic extract of Cardiospermum halicacabum Linn. might prove to be a useful memory restorative agent in the treatment of dementia seen in elderly.

Studies with the herbal plant in Indonesia were also developed for preventive and curative for MG. One of the therapeutic developments for $\mathrm{MG}$ is using herbal ingredients of Acalypha indica (AI). In the previous study, the water extract of the roots of AI for animal models proved to have a neuroprotective effect [26]. For his studies, mechanisms of plant $\mathrm{AI}$ as therapies on MG were done by assessing the autonomic condition on heart muscle will be tested. We want to know the effect extract of roots $\mathrm{AI}$ against the $\mathrm{AChR}$ and enzyme acetylcholinesterase in animal models NMJ-MG (Sprague-Dawley rats were injected with rocuronium bromide) on the autonomic nervous system on heart muscle, in this case, is heart rate (HR).

\section{METHODS}

\section{Extraction process}

The dry roots of AI were collected from Depok and had been identified at Lembaga Ilmu Pengetahuan (LIPI, Indonesian Institute of Sciences) Bogor. These roots were dried and powdered. The powder was macerated by ethanol $70 \%$ for $24 \mathrm{~h}$. Subsequently, the residue was remacerated 3 times by the same solvent, and the extract was mixed with previous ones. The collected extract was then concentrated by rotary vacuum evaporator. The dose of $\mathrm{AI}$ in this study was $150 \mathrm{mg} / \mathrm{kg} /$ body weight (BW). The extract was dissolved in aqua dest to get the appropriate dilution to administer orally just before the treatment exposure on each day.

\section{Treatment}

Animal involved in this experimental study was 36 Sprague-Dawley male rats, $8 \mathrm{w}$ of age, and 150-200 g. The rats were adapted into the experimental cages at the room temperature of $24^{\circ} \mathrm{C}$, for a week before and during treating. They were divided into six groups of an experiment, randomly. For this experiment used rocuronium (rocu), prostigmine (prost), and AI as compared with the HR. Rocuronium is a muscle relaxants non-depolarizing (competitive inhibitors) that bind to nicotinic-cholinergic receptors but does not cause depolarization, blocking acetylcholine, and occupied it, whereas prostigmine is a cholinesterase inhibitor used in the treatment of MG and to reverse the effects of muscle relaxants. Extract AI estimated can neutralize toxin caused by autoimmune and used as a therapy MG. Group control (normal) received CMC-Na Sol.1\%.
The treatment divided into two set, $\mathrm{AI}$ as a curative treatment and $\mathrm{AI}$ as a preventive. As a curative treatment, rats divided into three groups. Rats in group rocu as injected with rocuronium intraperitoneal $10 \mathrm{mg} / \mathrm{kg}$ BW as a control negative; group rocu + pros was injected first with rocuronium then after $10 \mathrm{~min}$ injected with prostigmine (as a positive control); and group rocu + AI was injected first with rocuronium then after 10 min was given $\mathrm{AI}$ extract.

As a preventive, rats divided into three groups. Rats in group rocu as injected with rocuronium intraperitoneal $10 \mathrm{mg} / \mathrm{kg} \mathrm{BW}$, group pros + rocu was injected first with prostigmine then after 10 min injected with rocuronium; and group AI + rocu was given AI extract $250 \mathrm{mg} / \mathrm{kg}$ BW first then after 30 min was injected with rocuronium. The HR was measured $10 \mathrm{~min}$ after giving the treatment. The treatment was given for 3 days, at the end of day 3, each rat was sacrificed under anesthesia.

\section{Statistical analysis}

Calculations were done with the statistical package SPSS, version 12.0. Data were presented as a mean \pm standard deviation. Unpaired two-sided Student's t-test was utilized for comparison among means of normally distributed parameters, while Mann-Whitney U test was for all other cases. Correlations were assessed using Pearson's and Spearman's methods for normally and non-normally distributed data, respectively. For all tests, values of $\mathrm{p}<0.05$ were considered statistically significant.

\section{RESULT AND DISCUSSION}

\section{HR}

The increase in HR ( $\mathrm{p}=0.0302)$ occurred with injection rocu in control on day 1 , while HR giving prostigmine in mice that received rocu first does not decrease significantly $(\mathrm{p}=0.5525)$ (Fig. 1a). Furthermore, the effects of injection rocu in group rocu + AI, HR increased significantly $(p=0.0137)$ and by given AI found a decline in HR but not significant ( $\mathrm{p}=0.6205)$ (Fig. 1a).

On the $2^{\text {nd }}$ day of trial found an increase in HR significantly $(\mathrm{p}=0.0019)$ in rocu group (Fig. 1b). Furthermore, in the group rocu + prost after the administration of rocu cause increased of HR significantly $(p=0.0335)$, whereas HR after injection of prostigmine does not decreased significant $(\mathrm{p}=0.5699)$ (Fig. 1b). Administration of rocu on group rocu + AI there was no significant increase in HR $(p=0.3762)$, and then after giving $\mathrm{AI}, \mathrm{HR}$ did not occur significant differences (p=0.4235) (Fig. 1b).

Trial on the day 3 , the effect of rocu on rocu group causes an increase in HR ( $p=0.0015)$, while the administration of rocu for the group rocu + pros, HR found increased significantly $(\mathrm{p}=0.0142)$ but after giving prost, HR decreased not significant $(p=0.3404$ ) (Fig. 1c). In the group rocu $+\mathrm{AI}, \mathrm{HR}$ rocu not significant $(\mathrm{p}=9646)$, and subsequently by AI, HR decreased but also not significant ( $\mathrm{p}=0.8967)$ (Fig. 1c).

The increase in HR $(\mathrm{p}=0.0302)$ occurred with injection rocu in control on day 1, while HR giving rocu in mice that received prostigmine first as a preventive does not decrease significantly ( $p=0.0570$ ) (Fig. 2a). Furthermore, the effects of injection rocu in mice that received AI first as a preventive, HR also was not increased significantly $(p=0.7525)$ (Fig. 2a).

On the $2^{\text {nd }}$ day of trial found an increase in HR significantly $(p=0.0019)$ in rocu group (Fig. 2b). While in the group prost + rocu, HR after giving rocu in mice that received prostigmine first as a preventive does not decrease significantly ( $p=0.4045$ ) (Fig. 2b). Furthermore, the effects of injection rocu in mice that received AI first as a preventive, HR also was not increased significantly $(\mathrm{p}=0.4843)$ (Fig. 2b).

Trial on the day 3 , the effect of rocu on rocu group causes an increase in HR ( $p=0.0015)$, while the administration of rocu in mice that received prostigmine first as a preventive does not increase (Fig. 2c). Furthermore, the effects of injection rocu in mice that received AI first as a preventive, HR also was not increased significantly ( $p=0.4843$ ) (Fig. 2c). 


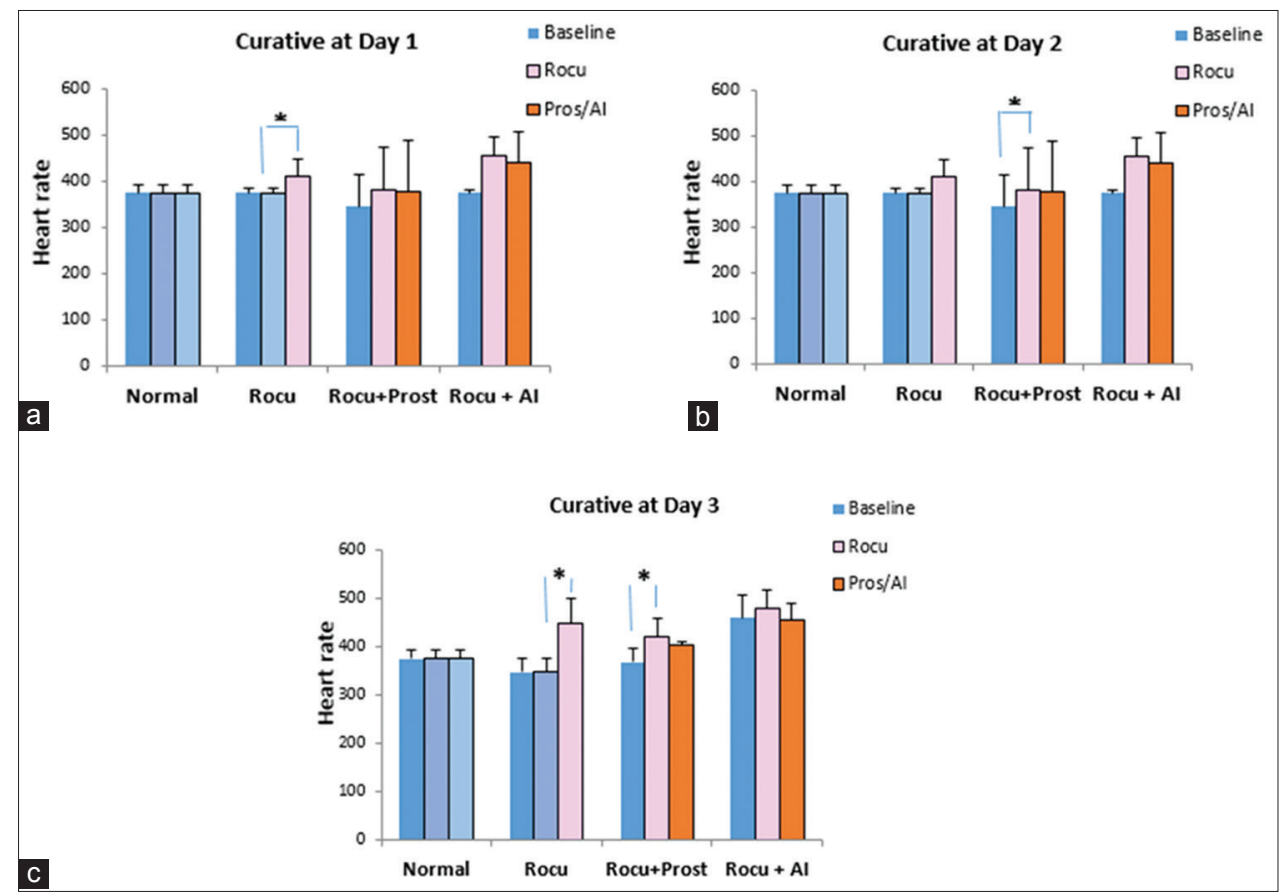

Fig. 1: Curative effect of Acalypha indica using prostigmine effect as a comparison. (a) Day 1 treatment, (b) Day 2 treatment, (c) Day 3 treatment. Label*: Significantly different $(P<0.05)$

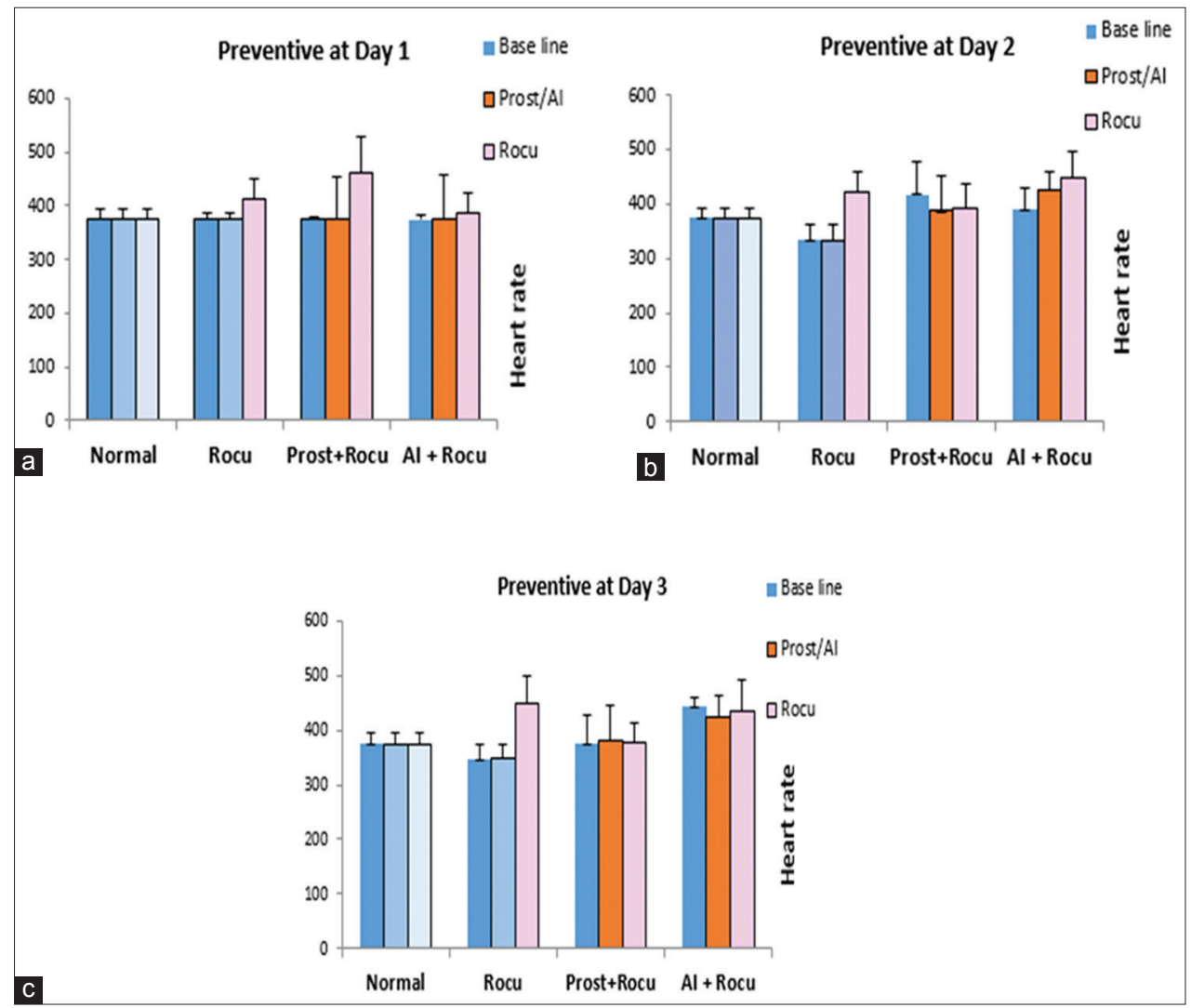

Fig. 2: Preventive effect of Acalypha indica using prostigmine effect as a comparison. (a) Day 1 treatment, (b) Day 2 treatment, (c) Day 3 treatment. Label*: Significantly different $(P<0.05)$

MG is a humoral immune attack to the skeletal muscle nicotinic AChRs (nAChRs) at the NMJ by autoantibodies [25]. The cardinal symptoms of MG is fatigue or fluctuating weakness in voluntary muscles with repeated or sustained exertion in the course of the day but improved by rest [27]. MG is an autoimmune disorder targeting skeletal muscles.
Striated cardiac muscle can be a target for immune attack manifesting as heart failure, arrhythmia, and sudden death [28]. A few studies were carried out to investigate cardiac involvement in patients with MG. Some reported non-specific ECG changes, Doppler imaging, and conventional echocardiography [29]. Another study demonstrated a 
reduced global heart ejection fraction in $40 \%$ of MG patients without known cardiac disease after exercise interpreted as a true association between MG and heart disease [30]. Depressed HR variability may be an early manifestation of autonomic neuropathy in patients with MG even in milder stages of the disease [4]. Heart muscle is a target for autoimmune inflammation in MG. Advancing age, thymoma, and antiKv1 antibodies appeared to be risk factors. Symptom overlap with myasthenia may result in failure to recognize cardiac involvement [30].

This research was conducted in SD rats using rocuronium, prostigmine, and $\mathrm{AI}$ as herbal therapy for MG to determine whether the root AI has a therapeutic effect as a binding Ab-AChRs for anima models proved to have effective therapies. Indeed, giving extract AI following administration of rocuronium tends to lower HR. AI Linn. has an effect similarly those that can lower HR with prostigmine although not significant in mice post-induction rocuronium. Giving extract AI as therapeutic action following administration of rocuronium tends to lower HR. Similarly, on trial. Furthermore, the use of $\mathrm{AI}$ as a preventive indicates that $\mathrm{AI}$ has an effect similar to the effect prostigmine which can prevent an increase in HR in rats will be induced by rocuronium. These results indicate the need for routine evaluation of autonomic functions in patients with MG both to identify patients at high risk for earlier consideration of cardioprotection and long-term followup studies. Furthermore, on the basis of these results using drugs rocuronium, prostigmine, and $\mathrm{AI}$ are associated with $\mathrm{HR}$ on EAMG, AI has the same effect with prostigmine. To know and learn more advanced study required.

CONCLUSION

AI Linn. has a similar effect with prostigmine as a positive control that can reduce HR although not significant in mice post-induction of rocuronium. AI Linn. also had the similar effect with prostigmine which could prevent an increase of HR in mice before rocuronium-induced. Our results clearly demonstrate AI as a promising candidate for the new agent for MG.

\section{ACKNOWLEDGMENTS}

Our studies reported in this research were supported by grants from DRPM, Universitas Indonesia, No. 1782/UN2.R12/PPM.00.00/2016.

\section{REFERENCES}

1. Conti-Fine BM, Milani M, Kaminski HJ. Myasthenia gravis: Past, present, and future. J Clin Invest 2006;116:2843-54.

2. Willcox N, Leite MI, Kadota Y, Jones M, Meager A, Subrahmanyam P, et al. Autoimmunizing mechanisms in thymoma and thymus. Ann N Y Acad Sci 2008;1132:163-73.

3. Johannessen KA, Mygland A, Gilhus NE, Aarli J, Vik-Mo H. Left ventricular function in myasthenia gravis. Am J Cardiol 1992;69:129-32.

4. Harmed SA, Mohamad KO, Adam M. Cardiac autonomic function in patients with myasthenia gravis: Analysis of the heart-rate variability in the time-domain. Neuroimmunol Neuroinflammation 2015;2:21-5.

5. Peric S, Rakocevic-Stojanovic V, Nisic T, Pavlovic S, Basta I, Popovic S, et al. Cardiac autonomic control in patients with myasthenia gravis and thymoma. J Neurol Sci 2011;307:30-3.

6. Mygland A, Aarli JA, Hofstad H, Gilhus NE. Heart muscle antibodies in myasthenia gravis. Autoimmunity 1991;10:263-7.

7. Hoch W, McConville J, Helms S, Newsom-Davis J, Melms A, Vincent A. Auto-antibodies to the receptor tyrosine kinase MuSK in patients with myasthenia gravis without acetylcholine receptor antibodies. Nat Med 2001;7:365-8

8. Calin C, Savu O, Dumitru D, Ghiorghiu I, Calin A, Capraru C, et al. Cardiac involvement in myasthenia gravis-is there a specific pattern?
Rom J Intern Med 2009;47:179-89.

9. Helgeland G, Luckman SP, Romi FR, Jonassen AK, Gilhus NE. Myasthenia gravis sera have no effect on cardiomyocytes in vitro. J Neuroimmunol 2008;201-202:74-9.

10. Puneeth CS, Chandra SR, Yadav R, Sathyaprabha TN, Chandran S. Heart rate and blood pressure variability in patients with myasthenia gravis. Ann Indian Acad Neurol 2013;16:329-32.

11. Senda Y, Sugimura K, Koike Y, Matsuoka Y, Takahashi A. Concurrence of acute autonomic and sensory neuropathy and myasthenia gravis-a case report and pathogenetic considerations. Rinsho Shinkeigaku 1989;29:332-5.

12. Pande R, Leis AA. Myasthenia gravis, thymoma, intestinal pseudoobstruction, and neuronal nicotinic acetylcholine receptor antibody. Muscle Nerve 1999;22:1600-2.

13. Vernino S, Cheshire WP, Lennon VA. Myasthenia gravis with autoimmune autonomic neuropathy. Auton Neurosci 2001;88:187-92.

14. Iwatsuki N, Hashimoto Y, Amaha K, Obara S, Iwatsuki K. Inotropic effects of non-depolarizing muscle relaxants in isolated canine heart muscle. Anesth Analg 1980;59:717-21.

15. Alvarez L, Escudero C, Silva L, Castillo-Olivares JL. Electrophysiological effects of atracurium and vecuronium on normal and denervated hearts. J Cardiothorac Vasc Anesth 1992;6:304-7.

16. Król T, Siondalska-Kunicka E. Haemodynamic side-effects of pancuronium. Anaesth Resusc Intensive Ther 1974;2:161-5.

17. Cornet JP, Abiad M, Coriat P, Saada M, Gosgnach ML, Viars P. Evaluation of the effects of rocuronium bromide on haemodynamics and left ventricular function in patients undergoing abdominal aortic surgery. Eur J Anaesthesiol Suppl 1994;9:78-81.

18. Cole RN, Reddel SW, Gervásio OL, Phillips WD. Anti-MuSK patient antibodies disrupt the mouse neuromuscular junction. Ann Neurol 2008;63:782-9.

19. Cole RN, Ghazanfari N, Ngo ST, Gervásio OL, Reddel SW, Phillips WD, et al. Patient autoantibodies deplete postsynaptic musclespecific kinase leading to disassembly of the ACh receptor scaffold and myasthenia gravis in mice. J Physiol 2010;588:3217-29.

20. Kawakami Y, Ito M, Hirayama M, Sahashi K, Ohkawara B, Masuda A, et al. Anti-MuSK autoantibodies block binding of collagen Q to MuSK. Neurology 2011;77:1819-26.

21. Shigemoto K, Kubo S, Maruyama N, Hato N, Yamada H, Jie C, et al. Induction of myasthenia by immunization against muscle-specific kinase. J Clin Invest 2006;116:1016-24

22. Mori S, Kubo S, Akiyoshi T, Yamada S, Miyazaki T, Hotta H, et al. Antibodies against muscle-specific kinase impair both presynaptic and postsynaptic functions in a murine model of myasthenia gravis. Am J Pathol 2012;180:798-810.

23. Richman DP, Agius MA. Treatment of autoimmune myasthenia gravis. Neurology 2003;61:1652-61.

24. Kassab RB, Bauomy AA. The neuroprotective efficiency of the aqueous extract of clove (Syzygium aromaticum) in aluminium-induced neutotoxicity. Int J Pharm Pharm Sci 2014;6:503-8.

25. Kukkar MR, Saluja AK, Sachdeva PD, Kukkar RR. In vivo investigation of the neuroprotective potential of Cardiospermum halicacabum Linn. Int J Pharm Pharm Sci 2014;6:64-6.

26. Purwaningsih $\mathrm{EH}$, Ibrahim $\mathrm{N}$, Zain $\mathrm{H}$. The nerve protection and in vivo therapeutic effect of Acalypha indica extract in frogs. Med J Indones 2007;19:96-102.

27. Lindstrom JM, Seybold ME, Lennon VA, Whittingham S, Duane DD. Antibody to acetylcholine receptor in myasthenia gravis. Prevalence, clinical correlates, and diagnostic value. Neurology 1976;26:1054-9.

28. Shivamurthy P, Parker MW. Cardiac manifestations of myasthenia gravis: A systematic review. IJC Metab Endocr 2014;5:3-6.

29. Furlund Owe J, Skulstad Davidsen E, Eide GE, Gerdts E, Gilhus NE. Left ventricular long-axis function in myasthenia gravis. J Neurol 2008;255:1777-84.

30. Rakocevic-Stojanovic V, Pavlovic S, Apostolski S, Lavrnic D, Vidakovic A, Kozarevic N. Importance of radionuclide exercise ventriculography in patients with myasthena gravis. Med Istrazivanja 1996;30:17-9. 